\title{
BDNF Variation and Mood Disorders: A Novel Functional Promoter Polymorphism and Val66Met are Associated with Anxiety but Have Opposing Effects
}

\author{
Xueying Jiang ',3 ${ }^{1,}$ Ke $\mathrm{Xu}^{2}$, Joelle Hoberman', Feng Tian', Aimee J Marko', Juwaria F Waheed ${ }^{2}$, \\ Claudia R Harris ${ }^{2}$, Ann M Marini ${ }^{3}$, Mary-Anne Enoch ${ }^{2}$ and Robert H Lipsky*, I \\ 'Section on Molecular Genetics, Laboratory of Neurogenetics, National Institute on Alcohol Abuse and Alcoholism, National Institutes of Health, \\ Bethesda, MD, USA; '2Section on Human Genetics, Laboratory of Neurogenetics, National Institute on Alcohol Abuse and Alcoholism, National \\ Institutes of Health, Bethesda, MD, USA; ${ }^{3}$ Department of Neurology, Uniformed Services University of the Health Sciences, Bethesda, MD, USA
}

\begin{abstract}
The brain-derived neurotrophic factor (BDNF) gene is critical for neuronal function and survival, and is likely to be important in psychiatric disorders. In this study, we used single-nucleotide polymorphism (SNP) discovery, functional analyses, and genetic association studies to better understand the potential role of BDNF sequence variation in behavior. Screening 480 unrelated individuals for SNPs and genotyping was performed in US Caucasian, American Indian, and African American populations. Lifetime DSM-III-R psychiatric diagnoses were assigned and the Tridimensional Personality Questionnaire (TPQ) was administered to measure anxious temperament (harm avoidance $(H A)$ ) and novelty seeking (NS). A novel SNP $(-28 \mid C>A)$ in promoter I was discovered that had decreased DNA binding in vitro and decreased basal reporter gene activity in transfected rat hippocampal neurons. The frequency of the $-28 \mathrm{I} A$ allele was 0.03 in a Caucasian sample, but was virtually absent in other populations. Association analyses in a community-based sample showed that individuals with the $-28 \mathrm{I}$ A allele ( 3 heterozygotes) had lower TPQ HA ( F =4.8, $p<0.05)$. In contrast, the Met 66 allele was associated with increased $\mathrm{HA}(\mathrm{F}=4 . \mathrm{I}, p=0.02)$ and was most abundant in individuals with both anxiety disorders and major depression $(p<0.05)$.

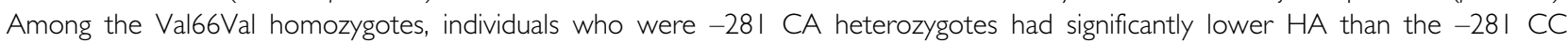
homozygotes $(p<0.01)$. Our results suggest that in this population, the low activity $-28 \mathrm{I} A$ allele may be protective against anxiety and psychiatric morbidity, whereas Met 66 may be a risk allele.

Neuropsychopharmacology (2005) 30, I353-136I, advance online publication, I6 March 2005; doi: | 0.1038/sj.npp. I 300703
\end{abstract}

Keywords: brain-derived neurotrophic factor; gene; polymorphism; promoter; anxiety; depression

\section{INTRODUCTION}

Survival and plastic responses of neurons are profoundly affected by availability of growth factors, particularly the neurotrophins. The neurotrophins are a large family of signaling factors that play critical functions in development, maintenance, and function in the CNS. Brain-derived neurotrophic factor (BDNF) is a member of the family of neurotrophins that functions in long-term potentiation (LTP) presynaptically (Xu et al, 2000) and postsynaptically (Kovalchuk et al, 2002) and in the maintenance of highfrequency stimulation-induced LTP in the adult rat brain (Messaoudi et al, 2002). Many of these effects are mediated

*Correspondence: Dr RH Lipsky, Neurogenetics, 5625 Fishers Lane, Room 3S32, MSC 9412, Bethesda, MD 20892-9412, USA, Tel: + I $30 \mid 402$ 559l, Fax: + I 301480 2839, E-mail: rlipsky@mail.nih.gov Received 28 September 2004; revised 10 January 2005; accepted 18 January 2005

Online publication: 20 January 2005 at http://www.acnp.org/citations/ NPPO I 2005040453/default.pdf by TrkB, the high-affinity receptor for BDNF, localized on cell bodies and dendrites as well as postsynaptically (Yan et al, 1997). In primary cultures of embryonic rat raphederived neurons, BDNF increases neuronal serotoninergic phenotype through TrkB-dependent pathways (Rumajogee et al, 2002). Complementing these data, overexpression of truncated forms of TrkB that are defective in signal transduction prevents antidepressant response (Saarelainen et al, 2003), a known target of serotonin activity.

At the gene level, human, mouse, and rat BDNF share similar exon-intron organization. We have determined that the human gene, which maps to chromosome position $11 \mathrm{p} 12-13$, is composed of at least six $5^{\prime}$ exons, each with its own putative promoter region, that are differentially spliced to a single $3^{\prime}$-terminal exon (Marini et al, 2004). The $3^{\prime}$ terminal codon contains the only functional splice acceptor site for splicing of the different $B D N F$ pre-mRNAs and encodes the entire sequence of mature BDNF. Thus, there is great potential for regulating BDNF expression at the level of transcription. Gene variants within BDNF promoter 
regions are currently unknown or uncharacterized. However, one coding region single-nucleotide polymorphism (SNP) has been well described in the proregion of the deduced polypeptide sequence that encodes a variant BNDF at codon 66 (Met 66Val). The Met 66 variant apparently affects processing of the pro-BDNF polypeptide and its release when neurons are activated (Egan et al, 2003).

From the foregoing discussion, it could be expected that $B D N F$ variation might influence behavior. However, mice with reduced BDNF levels do not display more anxious or depressive behaviors than normal mice (MacQueen et al, 2001; Chourbaji et al, 2004). Several recent studies have looked at the relationship between the functional $B D N F$ Val66Met variant and psychopathology in humans. The results have been conflicting. The Val66 allele has been associated with bipolar disorder in Caucasians (Sklar et al, 2002; Neves-Pereira et al, 2002; Geller et al, 2004) but not in Asians (Hong et al, 2003; Nakata et al, 2003). A haplotype incorporating Met 66 appeared to be protective against bipolar disorder (Sklar et al, 2002) or obsessive-compulsive disorder (OCD) (Hall et al, 2003). On the other hand, the Met 66 allele was strongly associated with anorexia nervosa (AN), restrictive type (Ribases et al, 2003), a disorder that shares features with OCD such as high harm avoidance (HA) and neuroticism. Yet again, one study has shown that the Val66 allele is associated with greater neuroticism (Sen et $a l, 2003$ ) and another has shown that there is no difference in HA between the genotypes (Tsai et al, 2004). Apart from differences in study design, genotyping, and data analysis (Schulze et al, 2003), one possibility for this lack of consensus is that other BDNF functional alleles may be present and have a role in psychopathology.

To better understand the complex regulation of BDNF, we used denaturing high-performance liquid chromatography (dHPLC) to identify candidate sequence variants in PCRamplified products obtained from a panel of genomic DNAs from 480 unrelated individuals of diverse clinical and ethnic backgrounds. DNA sequence variants were confirmed by direct sequence analysis of PCR products. With this approach, we identified a functional SNP in BDNF promoter 1 that was previously unidentified. We tested the relationship of this variant, and also the Val66Met polymorphism, in single allele-based association studies with psychiatric diagnoses and personality measures in a communityascertained sample of (predominantly) Caucasians.

\section{MATERIALS AND METHODS}

\section{Sequence Variant Detection}

To screen for SNPs, a PCR-based 'resequencing' strategy was used that incorporated dHPLC followed by direct sequence analysis. Genomic DNA was amplified from a total of 480 unrelated individuals across the $5^{\prime}$-flanking region of human $B D N F$ promoter 1. The screening sample was ethnically diverse, representing Caucasians, Asians, African Americans, and Native Americans, and a clinically diverse group, representing schizophrenia, OCD, alcoholism, depression, AN, and normal controls. Primers were based on the reference sequence (GenBank accession number AC087446). A $404 \mathrm{bp}$ amplification product from the $5^{\prime}$ flanking region was obtained using the following primer pairs: forward primer, 5'-GCCTCTCGCCTAGTCATCAGT3'; reverse primer, 5'-AAGAAAACCTTCGCCTTGTCA-3'. Reaction mixtures contained $100 \mathrm{ng}$ of genomic DNA; $0.2 \mathrm{mM}$ each of dATP, dCTP, and dTTP; $0.1 \mathrm{mM}$ dGTP; $0.1 \mathrm{mM} 7$-deaza-2'-dGTP; $0.4 \mu \mathrm{M}$ of each primer; $10 \mathrm{mM}$ Tris ( $\mathrm{pH} 8.3$ ); $50 \mathrm{mM} \mathrm{KCl} ; 1.5 \mathrm{mM} \mathrm{MgCl}_{2}$, and $1 \mathrm{U}$ Taq DNA polymerase in a final volume of $25 \mu \mathrm{l}$. DNA was denatured at $95^{\circ} \mathrm{C}$ for $5 \mathrm{~min}$. PCR, consisting of 35 cycles of annealing, was at $57^{\circ} \mathrm{C}$ for $30 \mathrm{~s}$ and extension was performed at $72^{\circ} \mathrm{C}$ for $1 \mathrm{~min}$. PCR was terminated by extension at $72^{\circ} \mathrm{C}$ for $10 \mathrm{~min}$. Conditions for dHPLC were described by Rudolph et al (2002). Prior to screening, products were purified using the MiniElute ${ }^{\mathrm{TM}}$ PCR Purification Kit (Qiagen, Chatsworth, CA). Briefly, PCR samples were denatured at $95^{\circ} \mathrm{C}$ for $5 \mathrm{~min}$ and then cooled to $65^{\circ} \mathrm{C}$ over a period of $30 \mathrm{~min}$ to enhance formation of DNA heteroduplexes. Samples were then analyzed on a Transgenomic HPLC system (Omaha, NE) with the DNASep ${ }^{\mathrm{TM}}$ HPLC column. The HPLC system consisted of a cooled 96-well autosampler, column oven, pumps, degasser, variable wavelength UV detector, $20 \mu \mathrm{l}$ sample loop, and a PC-based data collection system. The buffers were as follows: buffer A, $10 \mathrm{mM}$ TEAA (tri-ethyl ammonium acetate), $\mathrm{pH}$ 7.4; and buffer B, $10 \mathrm{mM}$ TEAA and 25\% acetonitrile. The loading buffer consisted of $10 \%$ acetonitrile for the DNASep column. Melting temperatures and buffer gradients were determined using the Transgenomic WAVEMAKER ${ }^{\mathrm{TM}}$ melting temperature prediction software. Heterozygous sequence variants were revealed when heteroduplex peaks were observed in addition to the common homoduplex peaks.

\section{DNA Sequence Analysis}

PCR samples with dHPLC elution profiles showing heteroduplex peaks were selected for direct bidirectional sequence analysis. Typically, the $10 \mu \mathrm{l}$ sequencing reaction mixture contained $4 \mu$ BigDye Terminator RR Mix (ABI, Foster City,

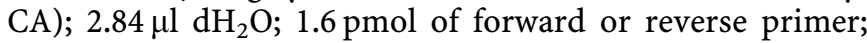
and $3 \mu \mathrm{l}$ of purified PCR amplicon. Cycle conditions for sequencing were 25 cycles consisting of denaturation at $96^{\circ} \mathrm{C}$ for $10 \mathrm{~s}$, annealing at $50^{\circ} \mathrm{C}$ for $5 \mathrm{~s}$, and extension at $60^{\circ} \mathrm{C}$ for $4 \mathrm{~min}$. Sequencing reaction products were purified using Performa DTR (Edge BioSystems, Gaithersburg, MD) columns, dried, diluted with $25 \%$ formamide $(\mathrm{v} / \mathrm{v})$, denatured at $95^{\circ} \mathrm{C}$ for $5 \mathrm{~min}$, and analyzed on a 3100 Genetic Analyzer (ABI, Foster City, CA).

\section{Genotyping}

Genotyping was performed using a $5^{\prime}$-exonuclease assay with allele-specific fluorescence detection probes. We designed an assay to detect each allele of the $-281 \mathrm{C}>\mathrm{A}$ SNP located at nucleotide position 83757 of the reference sequence (NCBI accession number AC087446; assigned NCBI submitted SNP (ss) reference ss32476175). The probes were fluorescently labeled with either FAM or VIC at the $5^{\prime}$-end and linked to a nonfluorescent quencher (MGB) at the $3^{\prime}$-end. Amplification primers were: forward, 5'-CGGCGCTGATAAGCAACA-3'; and reverse, 5' -GTAAGA AAACCTTCGCCTTGTCA- $3^{\prime}$. The sequence of the allelespecific detection probes were: $\mathrm{C}$ allele (MGB), $5^{\prime}$-TTCCCC 
AGCGGTC- ${ }^{\prime}$; and A allele (MGB), $5^{\prime}$-TTCCCCAGAGGTC$3^{\prime}$. BDNF Val66Met genotypes were also determined using a $5^{\prime}$-exonuclease allelic discrimination assay. The assay was based on Reference SNP ID: rs6265 (Celera ID hCV11592758, Assays-on-Demand C_11592758_10, Applied Biosystems, Foster City, CA). Genotyping reactions (5 $\mu \mathrm{l})$ were performed in 384-well plates containing $10 \mathrm{ng}$ of genomic DNA, $0.5 \mu \mathrm{M}$ of primers, $0.2 \mu \mathrm{M}$ of probes, and $2.5 \mu \mathrm{l}$ of Master Mix (Applied Biosystems Inc.). The reaction thermal cycle program consisted of $50^{\circ} \mathrm{C}$ for $2 \mathrm{~min}, 95^{\circ} \mathrm{C}$ for $10 \mathrm{~min}$, followed by $40 \mathrm{cycles}$ of $95^{\circ} \mathrm{C}$ for $15 \mathrm{~s}, 59$ or $60^{\circ} \mathrm{C}$ for $1 \mathrm{~min}$. End point amplification genotypes were determined using an Applied Biosystems 7900 Sequence Detector with Sequence Detection System 2.0 software. Genotyping accuracy was verified by regenotyping at least $10 \%$ of the DNA samples, randomly selected. Genotyping accuracy was $>99 \%$ and genotyping completion was $99 \%$.

\section{Cell Culture}

Primary neurons were prepared from the hippocampi that were removed from the brains of embryonic day 18 (E18) rats. Tissue was dissociated by mild trypsination and trituration as described (Mattson et al, 1993). Hippocampal cells were then seeded onto poly-L-lysine-coated $60-\mathrm{mm}$ culture dishes for transfection experiments. All experimental treatments were performed on 7-to 8-day-old cultures, which contained $95 \%$ neurons.

\section{Electrophoretic Mobility Shift Assays (EMSA)}

Nuclear extracts were prepared as described previously (Lipsky et al, 2001). Protein content was determined using a bicinchoninic acid colorimetric assay (Pierce, Rockford, IL) and protein content was equalized by dilution. Primary rat hippocampal neuron nuclear extracts were examined for DNA binding activity by incubating $5 \mu \mathrm{g}$ of protein with $\left[\gamma{ }^{33} \mathrm{P}\right]-\mathrm{ATP}$ (Perkin-Elmer Life Science) probes. DNA probes were generated by annealing complementary oligonucletide sequences corresponding to each $B D N F$ promoter 1 allele. The $\mathrm{C}$ allele oligonucleotide sequence (upper strand) was: $5^{\prime}$-CAAGTTCCCCAGcGGTCTTCC- ${ }^{\prime}$. The A allele sequence (upper strand) was: $5^{\prime}$ CAAGTTCCCCAGaGGTC TTCC $-3^{\prime}$ (the lower case letter indicates the position of the SNP). The double-stranded oligonucleotides were labeled with $\left[\gamma_{-}{ }^{33} \mathrm{P}\right]$-ATP using T4 polynucleotide kinase (Promega, Madison, WI) followed by purification through a Bio-Spin 30 chromatography column (BIO-RAD). Binding assays were performed for $20 \mathrm{~min}$ at room temperature using $2 \mu \mathrm{l}$ nuclear extract $(5 \mu \mathrm{g}$ total protein) in $15 \mu \mathrm{l}$ reactions containing binding buffer (10 mM HEPES ( $\mathrm{pH} 7.8), 50 \mathrm{mM}$ $\mathrm{KCl}, 5 \mathrm{mM} \mathrm{MgCl} 2,1 \mathrm{mM}$ EDTA, $5 \%$ glycerol), $1 \mathrm{mM} \mathrm{DTT}$, $0.25 \mu \mathrm{g}$ poly[dI:dC] and $1 \mu \mathrm{l}$ radiolabeled probe $(1.75 \mathrm{pmol}$; 100000 c.p.m./ $\mu$ l). In competition experiments, unlabeled competitor $(100 \times$ molar excess $)$ was included with the nuclear extract for $10 \mathrm{~min}$ prior to the addition of labeled probe.

\section{Reporter Gene Constructs, Transfection, and Expression Assays}

A genomic DNA sample from the sequence variant detection panel (above) that was confirmed to be heterozygous for the BDNF promoter $1-281 \mathrm{C} / \mathrm{A}$ SNP was selected to produce a $677 \mathrm{bp}$ PCR product for subsequent cloning into a reporter gene plasmid. The forward amplification primer incorporated a BglII restriction endonuclease cleavage site, while the reverse amplification primer incorporated a BamHI site for directional cloning into BglII/BamHI-digested pDsRed2.1 (Promega, Madison, WI). The PCR primer sequences were: forward, 5'-TCAGATCTAAGTCACTTACTCGCCCC-3'; and reverse, $5^{\prime}$-ATGGATCCGACAAAGCAACTGGCATC- $3^{\prime}$. Selection and propagation of $B D N F$ promoter 1-containing DsRed reporter plasmids was performed using standard molecular techniques. Sequences of inserts were verified by direct sequencing. Neurons were cotransfected with a combination of $\mathrm{p} b d n f$-DsRed constructs with either the $\mathrm{C}$ or A allele pCMV-GFP at a ratio of 2:1 using Lipofectamine 2000 (Invitrogen, Carlsbad, CA). Cells were maintained in 24-well plates for 3 days and then transfected using Lipofectamine 2000 according to the manufacturer's procedure. At $24 \mathrm{~h}$ after transfection, cells were treated with glutamate, and $36 \mathrm{~h}$ after treatment, ratios of GFP/RED protein were measured using Openlab software (Improvision Inc., Lexington, MA) and corrected for transfection efficiency.

Cells were assayed for fluorescence $48 \mathrm{~h}$ after transfection. Expression of DsRed by transfected neurons was monitored using an Olympus IX70 microscope (Olympus America, Melville, NY) interfaced with a Hamamatsu ORCA-ER digital camera (Hamamatsu, Tokyo, Japan). Fluorescence intensity measurements were performed using Openlab software (Improvision Inc.) and normalized for transfection efficiency using green fluorescence protein.

\section{Populations}

Four population samples were genotyped for the functional $B D N F$ promoter variant: (a) 208 predominantly Caucasian participants (Bethesda), (b) 347 Plains American Indians, (c) 171 Southwestern American Indians, and (d) 130 African Americans. Written informed consent was obtained according to human research protocols approved by the human research committee of the National Institute on Alcohol Abuse and Alcoholism, NIH for populations (a), (b), and (c), and by the National Institute of Mental Health, Rutgers University for population (d). The Tribal Councils of the two American Indian tribes also approved the protocols and consent forms.

Allele frequencies were sufficiently high for phenotypegenotype analyses in only the Bethesda population and therefore detailed methodology is only provided for this population.

\section{Participant Ascertainment}

In all, 208 paid volunteers were recruited (119 women and 89 men) from the general population of the Washington, DC/Baltimore, Maryland area by newspaper advertisements. Participants were enrolled in the study if they had a particular family structure (two living parents and at least two siblings) required for analysis of genetic transmission in another study (Enoch et al, 1999), and did not have the following exclusion criteria: a history of brain trauma with 
loss of consciousness, neurological disease, or recent ingestion of psychotropic drugs.

Ethnic origin was self-identified. There were 193 Caucasians and 15 African Americans. The mean (SD) ages were: men $(n=89) ; 41.5$ (16.7) years, women $(n=119) ; 42.9$ (16.1) years.

\section{Psychiatric Diagnoses}

Blind-rated DSM-III-R lifetime psychiatric diagnoses (American Psychiatric Association, 1987) were available for 204/208 participants and were obtained from the Schedule for Affective Disorders and Schizophrenia-Lifetime Version (SADS-L) (Endicott and Spitzer, 1978), a structured interview administered by a psychiatric social worker, as described fully elsewhere (Enoch et al, 1999). In accordance with DSM-III-R criteria, care was taken to ensure that, if major depression (MD) or anxiety disorders were temporally or directly related to alcohol consumption, lifetime diagnoses were not assigned. Lifetime MD was diagnosed in $15 \%$ of men and $26 \%$ of women. In all, $22 \%$ of men and $30 \%$ of women had at least one lifetime anxiety disorder (generalized anxiety, panic disorder, OCD, phobia). A total of $34 \%$ of men and $15 \%$ of the women had alcohol use disorders (alcohol abuse or dependence). The ratio of dependence to abuse was 2.5:1 in both men and women.

\section{Dimensional Measures of Personality}

Tridimensional Personality Questionnaires (TPQ) (Cloninger 1987) were completed by 153 participants. The TPQ provides dimensional measures of three components of personality: harm avoidance (HA), novelty seeking (NS), and reward dependence. $\mathrm{HA}$ is a measure of the tendency to become anxious. There are four HA subscales: anticipatory worry (HA1), fear of uncertainty (HA2), shyness (HA3), and fatigability (HA4).

\section{Statistical Analyses}

Analysis of variance (ANOVA) was used to determine differences in TPQ scores across genotypes. For individual SNP association analyses, genotype and allele frequencies in cases and controls were compared by $\chi^{2}$ tests. As this was an exploratory study, a Bonferroni correction, taking in account the two polymorphisms, was not performed. This correction may be too stringent to detect the effect of a susceptibility gene on HA.

We included the 15 African Americans together with the 193 Caucasians in the analyses. It is important to recognize that both self-identified black and white Americans are genetically admixed. Furthermore, there is no evidence that black and white Americans differ in anxiety or the prevalence of MD and anxiety disorders. Excluding the 15 African Americans did not alter the HA scores across genotypes for either polymorphism nor did it alter the relationships between psychiatric diagnosis and genotype or allele frequencies. The analyses were therefore performed on all 208 participants rather than arbitrarily excluding those who self-identified as African American. For expression analyses, SDs were obtained from five independent experiments. One-way ANOVA and Tukey's post hoc test were used for comparisons of multiple groups.

\section{RESULTS}

\section{Identification of a Novel SNP within BDNF Promoter 1}

Resequencing of the $5^{\prime}$-end of $B D N F$ revealed a novel, $\mathrm{C}>\mathrm{A}$ SNP occurring $281 \mathrm{bp}$ upstream of the proposed transcription start site for exon 1 . The $\mathrm{C}>\mathrm{A}$ substitution was identified by direct sequencing and was subsequently confirmed by $5^{\prime}$-exonuclease assay using allele-specific detection probes. The SNP is located at nucleotide position 83757 of the reference sequence (NCBI Accession number AC087446).

The frequency of the rare allele was: (a) Bethesda (193/208 Caucasian) 0.03, (b) Plains American Indians 0.004, (c) Southwestern American Indians 0.00, and (d) African Americans 0.004 .

\section{$B D N F-281$ A Allele Causes the Loss of a Specific DNA Binding Activity}

To determine if the polymorphism had an effect on DNA binding activity, we performed EMSAs using nuclear extracts prepared from rat hippocampal neurons. Three specific DNA-protein complexes were seen with a doublestranded DNA probe containing the $\mathrm{C}$ allele, with the loss of a specific band using a BDNF DNA probe containing the $A$ allele (Figure 1, panel a). The addition of unlabeled competitor DNA to the $\mathrm{C}$ probe resulted in disappearance of the three specific complexes (Figure 1, panel a). However, an unlabeled A allele competitor DNA in a crosscompetition experiment failed to prevent the formation of a proteinDNA complex with the $C$ probe (Figure 1, panel b). As a control, addition of either $\mathrm{C}$ or A double-stranded DNAs failed to prevent the appearance of a specific band with a Sp1 consensus binding site when used as competitors with an HEK cell nuclear extract enriched for Sp1 (Figure 1, panel c).

\section{The -281 A Allele Reduces Basal BDNF Promoter Activity in Hippocampal Neurons}

Genotype-influenced BDNF expression was measured in neurons transfected with $\mathrm{C}$ or A allele containing DsRed reporter plasmids (Materials and methods). For neurons grown under basal conditions, the $-281 \mathrm{C}$ allele reporter plasmid showed greater fluorescence intensity compared with the A allele reporter (Figure 2, panel a) and two times greater expression relative to neurons transfected with the $\mathrm{A}$ allele reporter plasmid (Figure 2, panel b).

Glutamate receptors play an important role in synaptic plasticity and learning and memory (Lynch, 2004). BDNF synthesis is enhanced in cortical and hippocampal neurons both in vitro and in vivo when NMDA and non-NMDA receptors are activated, causing an influx of extracellular $\mathrm{Ca}^{2}$ (Tao et al, 1998; Tao et al, 2002; Tabuchi et al, 2002). Promoter 1-dependent $B D N F$ transcription is known to be stimulated, at least in part, by increases in intracellular $\mathrm{Ca}^{2+}$ (Murray et al, 1998; Tabuchi et al, 2000). Therefore, we wanted to determine if hippocampal neurons carrying 
a

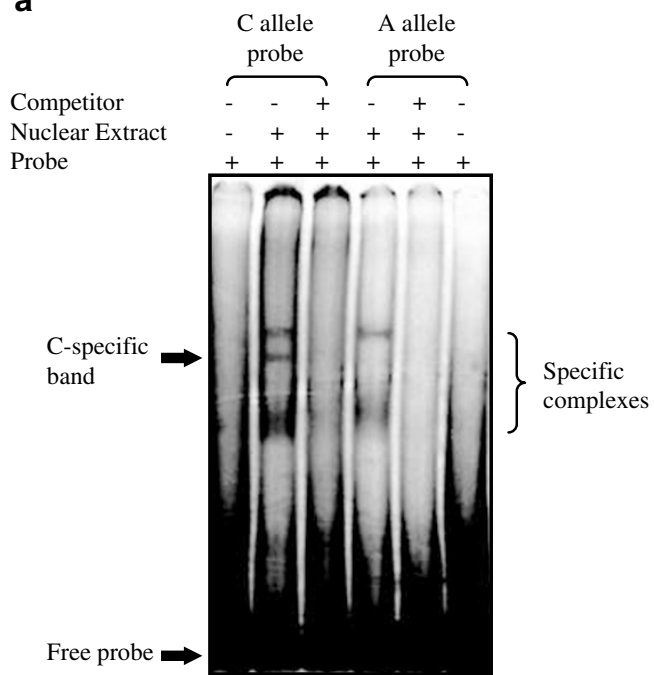

b

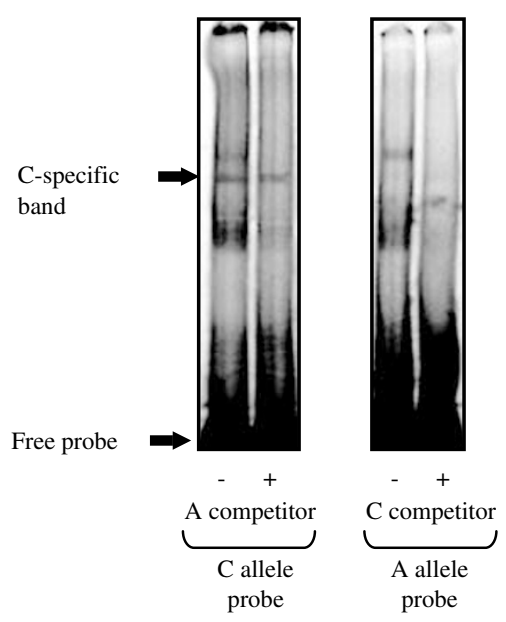

C

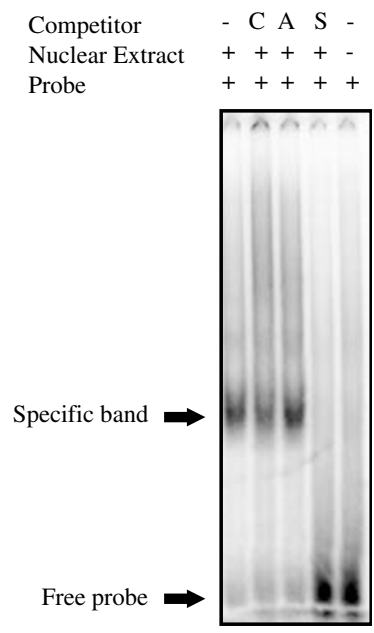

Figure I The -28I A allele causes a loss of a specific DNA binding activity by EMSA (panel a). Nuclear extracts were prepared from primary rat hippocampal neurons and stored at $-80^{\circ} \mathrm{C}$ until use. Single-stranded, complementary, $21 \mathrm{nt}$ oligonucleotide sequences were annealed to form doublestranded probes. DNA probes were generated by annealing complementary oligonucleotide sequences corresponding to each BDNF promoter I allele. The $C$ allele oligonucleotide sequence (upper strand) was: 5'-CAAGTTCCCCAGcGGTCTTCC-3'. The A allele sequence (upper strand) was: 5'-CAAGTTCCCCAGaGGTCTTCC-3' (the lower case letter indicates the position of the SNP). [ $\gamma^{-3}$ P]-ATP (Perkin-Elmer Life Science) probes were generated by labeling the double-stranded DNAs with T4 polynucleotide kinase (Promega, Madison, WI). Binding assays were performed for 20 min at room temperature using $5 \mu \mathrm{g}$ total protein in $15 \mu$ reactions containing binding buffer $(10 \mathrm{mM} \mathrm{HEPES}(\mathrm{pH} 7.8), 50 \mathrm{mM} \mathrm{KCl}, 5 \mathrm{mM} \mathrm{MgCl}, \mathrm{ImM} \mathrm{EDTA}, 5 \%$ glycerol), I mM DTT, $0.25 \mu \mathrm{g}$ poly[dl:dC] and $1.0 \mu \mathrm{l}$ radiolabeled probe ( $1.75 \mathrm{pmol}$; 100000 c.p.m./ $\mu$ l). In competition experiments, the corresponding unlabeled competitor for either allele ( $100 \times$ molar excess) was included with the nuclear extract for 10 min prior to the addition of the labeled probe. The $\mathrm{C}$ allele-specific complex (band) is indicated by an arrow. Cross competition experiment (panel b). EMSA performed as in panel (a) with $\mathrm{C}$ allele and $\mathrm{A}$ allele double-stranded probes but using competitors of the opposite allele. The A allele competitor failed to block the appearance of the $\mathrm{C}$ allele-specific complex. $\mathrm{C}$ allele or A allele competitors fail to block SpI-dependent DNA binding activity. EMSA performed with HEK cell nuclear extract (enriched in SpI) and competition assays using a radiolabeled SpI double-stranded oligonucleotide (panel c). Addition of unlabeled double-stranded competitor oligonucleotides corresponding to an excess of the C allele (C), A allele (A), or SpI (S) are indicated at the top of the appropriate lane. Only the SpI competitor prevented the appearance of the protein-DNA complex seen without competitor (arrow).

either -281 promoter 1 allele in reporter plasmids could be activated by incubating the cells with glutamate. After treatment with $50 \mu \mathrm{M}$ glutamate, neurons with the $\mathrm{C}$ allele reporter plasmid increased transcriptional activity by approximately $30 \%$ compared to the untreated neurons transfected with the same plasmid (Figure 2, panel b). Neurons carrying the A allele reporter plasmid showed a $15 \%$ increase in transcription with glutamate treatment, although this change was not significant when compared to untreated neurons carrying the A allele reporter plasmid.

\section{Association of BDNF - 281 A with Decreased HA and no Psychiatric Diagnosis}

Phenotype-genotype analyses were undertaken on the Bethesda sample. TPQ scores were available for 153 participants, including 11 of the $13-281 \mathrm{C}>\mathrm{A}$ heterozygotes. An ANOVA revealed that these heterozygotes had lower TPQ HA $(\mathrm{F}(1,149)=4.8, p=0.03)($ Table 1$)$. There were lower scores in all four HA subscales, but the largest difference was in HA2, fear of uncertainty, $(\mathrm{F}(1,149)=8.4$, $p=0.004)$ followed by HA4, fatigability, $(\mathrm{F}(1,149)=4.3$, $p=0.04)$. HA decrements occurred in both men $(13.2 \pm 8.2$ vs $6.0 \pm 2.7)$ and women $(14.0 \pm 6.7 v s 11.4 \pm 6.9)$. There was no difference in NS between the two genotypes.

Of the 13-281 A heterozygous individuals, nine did not have a diagnosis of alcoholism, MD, or anxiety disorders compared with 90 of the 191 individuals with only the -281
$\mathrm{C}$ allele. Thus, there was a trend for the association of the variant allele with no psychiatric diagnosis $(0.69$ vs 0.47 , $\chi^{2}=2.4$, Fisher's exact $p$-value $=0.16$ ). The prevalence of psychiatric disease in the heterozygous individuals compared with individuals without the variant was: alcoholism, 0.08 vs 0.25 ; MD, 0.15 vs 0.22 ; and anxiety disorders, 0.23 vs 0.27 .

\section{Association of BDNF Val66Met with Increased HA and MD/Anxiety Disorders}

In contrast with the promoter variant, the Met 66 allele was associated with increased HA (F $(2,150)=4.1, p=0.02)$ (Table 2). The higher scores were seen in all four HA subscales, but the largest difference was in HA1, anticipatory worry, $(\mathrm{F}(2,150)=5.4, p=0.005)$, followed by HA2, fear of uncertainty, $(\mathrm{F}(2,150)=2.7, p=0.07)$. HA scores were increased in both women ( $\mathrm{val} / \mathrm{val} 13.1 \pm 6.6, \mathrm{val} / \mathrm{met}$ $16.3 \pm 6.5$, met/met $17.0 \pm 4.6)$ and men (val/val $12.0 \pm 7.5$, $\mathrm{val} / \mathrm{met} 12.5 \pm 10.1$, met/met $20.5 \pm 16.3)$. There was no difference in NS between the genotype groups.

The Met 66 allele was significantly more common (0.31) in the 24 individuals with diagnoses of both MD and anxiety disorders compared with individuals with: MD alone (0.13), $n=23$; anxiety disorders alone (0.13), $n=32$; and neither MD nor anxiety disorders (0.13), $n=128 \quad\left(\chi^{2}=10.8\right.$, $p=0.013,3 \mathrm{df})$. 


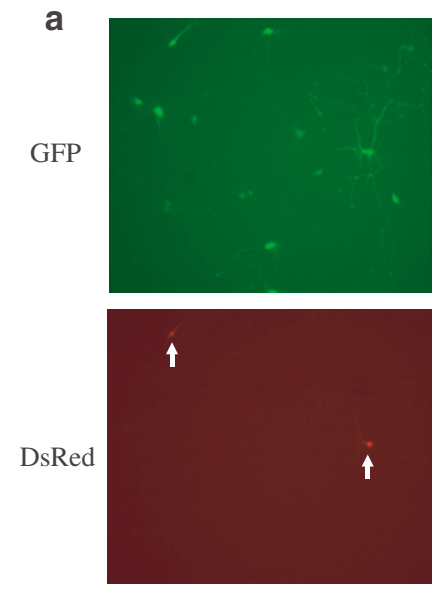

C allele
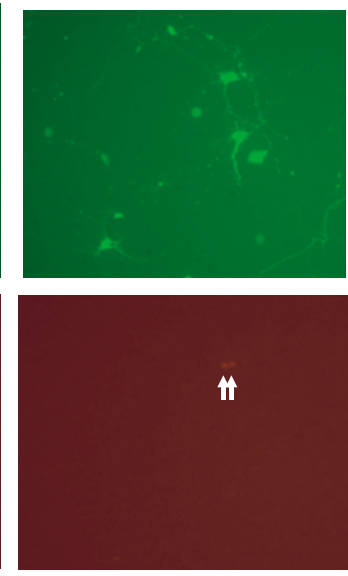

A allele

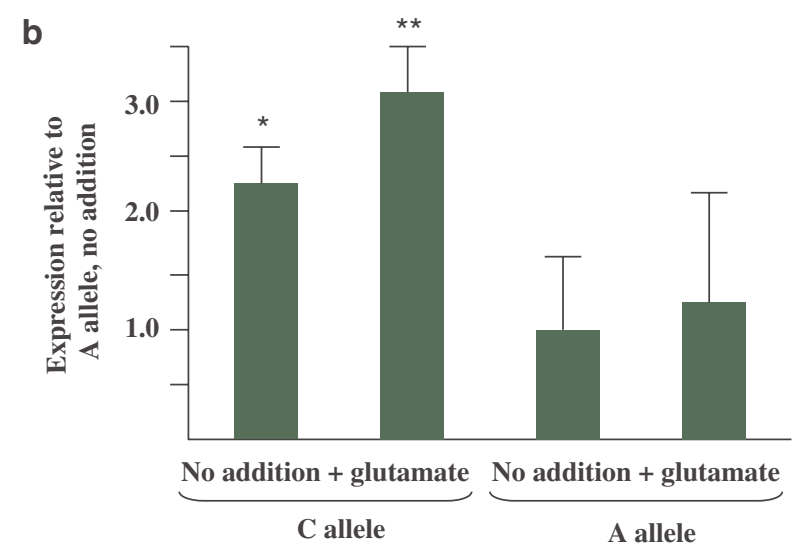

Figure 2 Promoter | activity in hippocampal neurons. Two pDsRed reporter plasmids containing a $678 \mathrm{bp}$ genomic segment of the human BDNF promoter I were constructed, one having the $-28 \mathrm{I} C$ allele and the other with the $-28 \mathrm{I} A$ allele (Materials and methods). Sequences of the inserts were verified by DNA sequencing. Primary rat hippocampal neurons were co-transfected with a combination of the bdnf- DsRed constructs (C or A allele) and pCMV-GFP at a ratio of 2: I. After $24 \mathrm{~h}$, cells were treated with glutamate, $36 \mathrm{~h}$ after treatment, ratios of GFP/RED protein were measured using Openlab software (Improvision Inc., Lexington, MA) and corrected for transfection efficiency. A fluorescent image of untreated hippocampal neurons expressing GFP and DsRed is shown in Panel a. Arrows indicate neurons producing DsRed. The $C$ allele allows for higher DsRed expression than the A allele. Quantitation of DsRed levels by $C$ allele or A allele BDNF promoter I reporter plasmids (panel b). The level of expression is given relative to the $A$ allele under basal conditions (no addition). ANOVA showed significant differences between four groups $(F=28.3, p=<0.000 \mathrm{I})$. Asterisks indicate significant differences in BDNF promoter I expression ( $* 0<0.05$ comparison of $C$ allele and $A$ allele pairs; *** $<0.0$ I comparison of glutamate-treated and -untreated pairs).

\section{Interactive Effects between BDNF $-281 \mathrm{~A}$ and $B D N F$ Val66Met Genotypes on HA}

It can be seen from Table 3 and Figure 3 that HA scores vary across the combined genotypes $(\mathrm{F}(4,141)=3.8, p=0.006)$, as do HA1 $(\mathrm{F}(4,141)=3.6, p=0.008)$ and HA2 $(\mathrm{F}(4,141)=$ $3.6, p=0.009)$. In particular, among the Val66Val homozygotes, individuals who were $-281 \mathrm{CA}$ heterozygotes had significantly lower $\mathrm{HA}$ than the $-281 \mathrm{CC}$ homozygotes $(\mathrm{F}(1,110)=7.1, p=0.009)$.
Table I Variation in TPQ Harm Avoidance Scores by BDNF Promoter I -28I C/A Genotype

\begin{tabular}{lrccccc}
\hline Genotype & N & HA & HAI & HA2 & HA3 & HA4 \\
\hline CC & 140 & $13.8 \pm 7.4$ & $3.7 \pm 2.7$ & $4.2 \pm 2.0$ & $3.0 \pm 2.2$ & $3.0 \pm 2.7$ \\
CA & II & $8.8 \pm 5.3$ & $2.5 \pm 2.3$ & $2.5 \pm 1.0$ & $2.5 \pm 2.7$ & $1.3 \pm 2.0$ \\
AA & 0 & & & & & \\
F $(1, \mid 49)$ & & 4.8 & 1.8 & 8.4 & 0.3 & 4.3 \\
P-value & & 0.03 & 0.187 & 0.004 & 0.562 & 0.04 \\
\hline
\end{tabular}

Total HA scores (mean $\pm \mathrm{SD}$ ) and subscales of the TPQ: HAI, anticipatory worry; HA2, fear of uncertainty; HA3, shyness; HA4, fatigability. ANOVA across two groups: genotypes CC vs CA.

HA scores converted to $Z$ scores:

$\begin{array}{llllllll}\text { HAscores } & 0 & 5 & 10 & 15 & 20 & 25 & 30\end{array}$

$\begin{array}{llllllll}\text { Zscores } & -3 & -2 & -1 & 0 & 1 & 2 & 3\end{array}$

Table 2 Variation in TPQ Harm Avoidance Scores by BDNF Val66Met Genotype

\begin{tabular}{lrccccc}
\hline Genotype & N & HA & HAI & HA2 & HA3 & HA4 \\
\hline Val66val & 117 & $12.7 \pm 7.0$ & $3.2 \pm 2.6$ & $3.9 \pm 2.0$ & $2.8 \pm 2.2$ & $2.7 \pm 2.6$ \\
Val66met & 33 & $15.3 \pm 7.9$ & $4.5 \pm 2.9$ & $4.4 \pm 1.8$ & $3.1 \pm 2.0$ & $3.5 \pm 3.0$ \\
Met66met & 3 & $22.3 \pm 9.5$ & $7.0 \pm 2.6$ & $6.3 \pm 1.2$ & $4.7 \pm 3.2$ & $4.3 \pm 4.0$ \\
F (2,150) & & 4.1 & 5.4 & 2.7 & 1.2 & 1.4 \\
P-value & & 0.02 & 0.005 & 0.07 & 0.31 & 0.25 \\
\hline
\end{tabular}

Total HA scores (mean \pm SD) and subscales of the TPQ: HAI, anticipatory worry; HA2, fear of uncertainty; HA3, shyness; HA4, fatigability.

ANOVA across three groups: genotypes val66val, val66met, and met66met. HA scores converted to $Z$ scores:

$\begin{array}{llllllll}\text { HAscores } & 0 & 5 & 10 & 15 & 20 & 25 & 30\end{array}$

$\begin{array}{llllllll}\text { Zscores } & -3 & -2 & -1 & 0 & \mid & 2 & 3\end{array}$

\section{DISCUSSION}

Functional candidate gene studies have successfully identified genes involved in several neuropsychiatric traits and disorders including Alzheimer's disease, Apo E (Corder et al, 1993); schizophrenia, COMT (Egan et al, 2001); and Parkinson's disease (Toda et al, 2003). In the case of mood disorders, as in MD, such prior knowledge is still rudimentary, but a growing body of data implicate genes that play a role in neuroplasticity, and neurogenesis may also play an important role in psychopathology (Nakagawa et al, 2002; Coyle and Duman 2003; Manji et al, 2003). Although many genes have direct roles in neuroplasticity and neurogenesis, only BDNF has been tested for association with mood disorders in large samples. Specifically, the Met 66 allele was part of a haplotype with an apparent protective effect against bipolar disorder (Sklar et al, 2002), a finding that was supported by two other studies (NevesPereira et al, 2002; Geller et al, 2004). In another study, a Met 66 haplotype was associated with protection against OCD (Hall et al, 2003). Both bipolar disorder and OCD are thought to have a pathophysiologic basis in serotonergic function (Tsuang et al, 2004; Murphy et al, 2004). Thus, at least one functional BDNF SNP is associated with behavioral disorders with serotonergic basis. 
Table 3 Interaction between BDNF Val66Met and -28I C>A Genotypes: Effects on TPQ Harm Avoidance

\begin{tabular}{|c|c|c|c|c|c|c|}
\hline Genotypes & $\mathbf{N}$ & Total HA & HAI & HA2 & HA3 & HA4 \\
\hline \multicolumn{7}{|c|}{ Val66Met, -28 I C>A } \\
\hline Met/met+CC & 3 & $22.3 \pm 9.5$ & $7.0 \pm 2.6$ & $6.3 \pm 1.2$ & $4.7 \pm 3.2$ & $4.3 \pm 4.0$ \\
\hline $\mathrm{Val} / \mathrm{met}+\mathrm{CC}$ & 29 & $15.4 \pm 8.0$ & $4.6 \pm 3.0$ & $4.4 \pm 1.9$ & $2.9 \pm 1.9$ & $3.5 \pm 3.0$ \\
\hline $\mathrm{Val} / \mathrm{met}+\mathrm{CA}$ & 2 & $17.5 \pm 3.5$ & $5.5 \pm 0.7$ & $3.5 \pm 2.1$ & $5.5 \pm 2.1$ & $3.0 \pm 4.2$ \\
\hline $\mathrm{Val} / \mathrm{val}+\mathrm{CC}$ & 103 & $13.3 \pm 7.1$ & $3.3 \pm 2.6$ & $4.1 \pm 2.0$ & $2.9 \pm 2.2$ & $2.9 \pm 2.6$ \\
\hline$F(4,|4|)$ & & 3.8 & 3.6 & 3.6 & 1.6 & 1.8 \\
\hline$P$-value & & 0.006 & 0.008 & 0.009 & 0.167 & 0.125 \\
\hline
\end{tabular}

Total HA scores (mean \pm SD) and subscales of the TPQ: HAI, anticipatory worry; HA2, fear of uncertainty; HA3, shyness; HA4, fatigability.

ANOVA across the five available genotypes. HA scores converted to $Z$ scores:

$\begin{array}{llllllll}\text { HAscores } & 0 & 5 & 10 & 15 & 20 & 25 & 30\end{array}$

$\begin{array}{llllllll}\text { Zscores } & -3 & -2 & -1 & 0 & 1 & 2 & 3\end{array}$

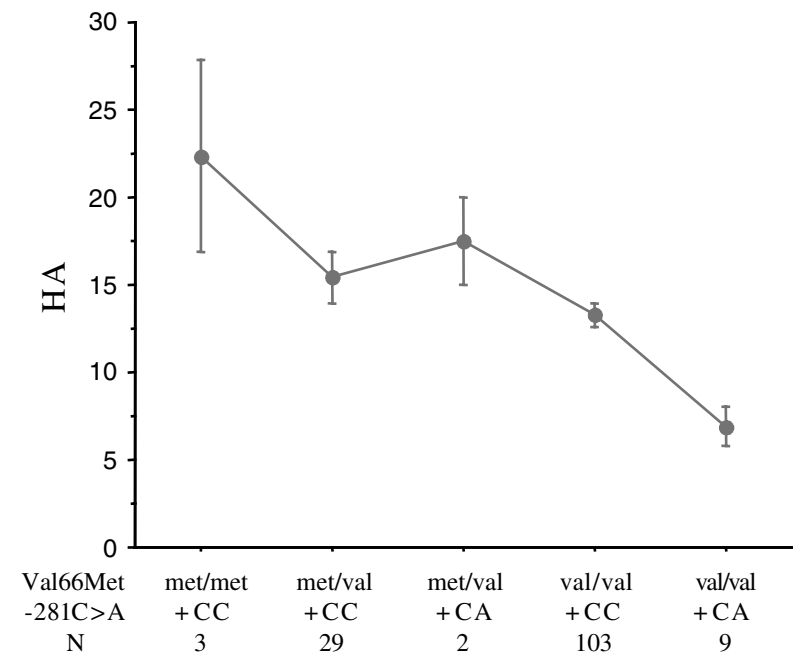

Figure 3 TPQ mean HA scores across joint genotypes: Val66Met and -28 I C >A. F $(4,|4|)=3.8, p=0.006$. Error bars: \pm I SE.

The BDNF gene shows complex transcriptional regulation. Transcriptional activation of $B D N F$ has been shown in rat cortical neurons through L-type voltage-dependent calcium channels and NMDA receptors (Tao et al, 1998; Tabuchi et al, 2002) and in rat cerebellar neurons acting through NMDA receptors (Marini et al, 1998) in vitro to activate $B D N F$ promoter 3 . Less is known about transcriptional activation of other $B D N F$ promoters, but for $B D N F$ promoter 1 , calcium-activated upstream stimulatory factor and cAMP-responsive element-binding protein sites, which are located approximately $110 \mathrm{nt} 5^{\prime}$ of the SNP described here, have been functionally characterized (Tabuchi et al, 2002).

By extending the search for candidate functional variants at $B D N F$ to include regulatory regions, we discovered a previously unknown variant within promoter 1 . The $\mathrm{C}>\mathrm{A}$ variant is located -281 from the inferred transcription start site for human $B D N F$ exon 1 . This region is highly conserved between mouse, rat, and human sequences, demonstrating $>90 \%$ nucleotide sequence identity between the three species. The nonvariant nucleotide $(\mathrm{C})$ at position
-281 in the human sequence is preserved in both rat and mouse, as are the flanking sequences $18 \mathrm{nt} 5^{\prime}$ and $63 \mathrm{nt} 3^{\prime}$ of the SNP. A search using three databases: MatInspector (Genomatrix) professional version 7.0, TFSEARCH version 1.3, and SIGNAL SCAN version 4.05 (Prestridge, 1991) for transcription factor binding sites failed to predict any known sites that incorporated either allele of the polymorphism, although an Sp1 site was predicted $10 \mathrm{nt} 3^{\prime}$ from the position of the SNP. It should be noted that neither EMSA allele-specific binding probe contained an Sp1 site, and thus would not be expected to compete for binding in that assay. Indeed, an Sp1 DNA target failed to compete with either of the BDNF promoter probes. None of the known functional regulatory sites for $B D N F$ promoter 1 are physically close to the SNP described in this study. Identifying the factor(s) that bind this site and regulates $B D N F$ expression is a high priority in future studies.

Phenotype-genotype analyses were undertaken on the Bethesda sample for the BDNF promoter $1-281 \mathrm{C}>\mathrm{A}$ and Val66Met variants. We found that the two SNPs had opposite effects. The $-281 \mathrm{C}>\mathrm{A}$ heterozygotes had lower $\mathrm{HA}$ and, in particular, lower HA2, fear of uncertainty. In support of this result was a trend for the association of the -281 A allele with the absence of any psychopathology. However, the Met 66 allele was associated with increased HA, particularly HA1, anticipatory worry, and also HA2. In addition, the Met 66 allele was more abundant in individuals with both anxiety and depression. When we looked at the effects of $-281 \mathrm{C}>\mathrm{A}$ on a constant Val66Met background, that is, in Val66Val homozygotes, we found that the $-281 \mathrm{C}>\mathrm{A}$ heterozygotes still had significantly lower HA, suggesting that this variant exerts effects independently of Val66Met. Our results support the idea that the $-281 \mathrm{~A}$ allele, in this community-ascertained population, may have a protective effect against anxiety and psychiatric morbidity, while the Met 66 allele has the opposite effect. However, because our study was based on a small sample population and because the frequency of the $B D N F-281$ A allele is low (0.03), our results must be treated with caution until replicated in larger data sets. Also, our results may have been influenced by population stratification, although for the reasons discussed earlier, we consider this unlikely. 
The individual contribution of the $-281 \mathrm{C}>\mathrm{A}$ polymorphism at the level of behavioral phenotypes remains to be understood. However, based on our preliminary results on the functional consequences of the $-281 \mathrm{~A}$ allele on $B D N F$ expression in vitro and our association with reduced anxious temperament, these results when taken together suggest that the $-281 \mathrm{C}>\mathrm{A}$ polymorphism may have an impact on neuronal function in vivo. It is possible that the 'protective' $-281 \mathrm{~A}$ allele may be counterbalanced by the Met 66 allele that was associated with increased HA and $\mathrm{MD} /$ anxiety disorders, but this possibility needs to be confirmed in a larger sample. As it appears that in Caucasians the extent of linkage disequilibrium across $B D N F$ is very high (Sklar et al, 2002; Hall et al, 2003; RHL unpublished data), we calculated pairwise $D^{\prime}$ and the square of the correlation coefficient $\left(r^{2}\right)$ between $-281 \mathrm{C}>\mathrm{A}$ and Val66Met using unphased haplotypes for estimating haplotype frequencies by an expectation maximization algorithm. Strong linkage disequilibrium was observed between the two markers, although the $r^{2}$ measure failed to correlate with the calculated $D^{\prime}$ value, most likely because the allele frequencies at the two markers were dissimilar (Hall et al, 2003; Devlin and Risch, 1995). Although the frequency of the -281 A allele was low (0.03) in the study population, it was on the same haplotype background as the Val66 allele (RHL, unpublished data). This suggests that reduced transcription from $B D N F$ promoter 1 could potentially affect expression of pro-BDNF Val (Egan et al, 2003, Chen et al, 2004). It is also possible that the A allele may decrease basal synthesis and release of BDNF in vivo. Basal BDNF synthesis and release does not appear to be affected by Val66Met (Egan et al, 2003; Chen et al, 2004). Thus, this promoter variant could contribute to reduced basal BDNF activity, which is associated with lower anxiety measures (such as HA). Alternatively, reduced expression of a proBDNF isoform with an uncleaved signal peptide that is predicted to be transcribed from promoter 1 could affect overall BDNF function (Marini et al, 2004). While the overall impact of this polymorphism is unclear given the number of promoters and the variety of regulatory mechanisms of $B D N F$, additional association and functional studies in larger sample populations should clarify how this promoter variant could potentially impact phenotype. For example, a power analysis revealed that approximately 40 -281 CA heterozygotes and $630-281$ CC homozygotes would be required to have at least $80 \%$ power of detecting a difference between groups in a larger study. Also, by using 'resequencing' approaches and follow-up functional studies of other $B D N F$ regulatory regions, it is anticipated that new functional variants will be discovered. Understanding the influence of these currently unknown loci that control $B D N F$ expression may lead to better understanding of the role of BDNF in behavior. It is also possible that individuals identified with a particular $B D N F$ haplotype(s) may benefit from targeted therapeutic interventions designed to reactivate neuronal plasticity and thereby overcome functional deficits.

\section{ACKNOWLEDGEMENTS}

This work was funded by intramural research grant Z01AA00325 from the National Institute on Alcohol Abuse and
Alcoholism, National Institutes of Health (RHL) and by grant F292BU from the Defense Brain and Spinal Cord Injury Program (AMM).

\section{REFERENCES}

American Psychiatric Association (1987). Diagnostic and Statistical Manual of Mental Disorders, 3rd edn, revised. American Psychiatric Association: Washington, DC. 567pp.

Chen Z-Y, Patel PD, Sant G, Meng C-X, Teng KK, Hempstead BL et al (2004). Variant brain-derived neurotrophic factor (BDNF) (Met66) alters the intracellular trafficking and activity-dependent secretion of wild-type BDNF in neurosecretory cells and cortical neurons. J Neurosci 24: 4401-4411.

Chourbaji S, Hellweg R, Brandis D, Zorner B, Zacher C, Lang UE et al (2004). Mice with reduced brain-derived neurotrophic factor expression show decreased choline acetyltransferase activity, but regular brain monoamine levels and unaltered emotional behavior. Brain Res Mol Brain Res 121: 28-36.

Cloninger CR (1987). A systematic method for clinical description and classification of personality variants. Arch Gen Psychiatry 44: $573-788$.

Corder EH, Saunders AM, Strittmatter WJ, Schmechel DE, Gaskell PC, Small GW et al (1993). Gene dose of apolipoprotein E type 4 allele and the risk of Alzheimer's disease in late onset families. Science 261: 921-923.

Coyle JT, Duman RS (2003). Finding the intracellular signaling pathways affected by mood disorder treatments. Neuron 38: 157-160.

Devlin B, Risch N (1995). A comparison of linkage disequilibrium measures for fine-scale mapping. Genomics 29: 311-322.

Egan MF, Goldberg TE, Kolachana BS, Callicott JH, Mazzanti CH, Straub RE et al (2001). Effect of COMT Val108/158 Met genotype on frontal lobe function and risk for schizophrenia. Proc Natl Acad Sci USA 98: 6917-6922.

Egan MF, Kojima M, Callicott JH, Goldberg TE, Kolachana BS, Bertolino A et al (2003). The BDNF val66met polymorphism affects activity-dependent secretion of BDNF and human memory and hippocampal function. Cell 112: 257-269.

Endicott J, Spitzer RL (1978). A diagnostic interview: the Schedule for Affective Disorders and Schizophrenia. Arch Gen Psychiatry 35: 837-844.

Enoch M-A, White K, Harris CR, Robin RW, Ross J, Rohrbaugh JW et al (1999). Association of low-voltage alpha EEG with a subtype of alcohol use disorders. Alcohol Clin Exp Res 23: $1312-1319$.

Geller B, Badner JA, Tillman R, Christian SL, Bolhofner K, Cook Jr $\mathrm{EH}$ (2004). Linkage disequilibrium in the brain-derived neurotrophic factor Val66Met polymorphism in children with a prepubertal and early adolescent bipolar disorder phenotype. Am J Psychiatry 161: 1698-1700.

Hall D, Dhilla A, Charalambous A, Gogos JA, Karayiorgou M (2003). Sequence variants of the brain-derived neurotrophic factor (BDNF) gene are strongly associated with obsessivecompulsive disorder. Am J Hum Genet 73: 370-376.

Hong CJ, Huo SJ, Yen FC, Tung CL, Pan GM, Tsai SJ (2003). Association study of a brain-derived neurotrophic-factor genetic polymorphism and mood disorders, age of onset and suicidal behavior. Neuropsychobiology 48: 186-189.

Kovalchuk Y, Hanse E, Kafitz KW, Konnerth A (2002). Postsynaptic induction of BDNF-mediated long-term potentiation. Science 295: 1729-1734.

Lipsky RH, Xu K, Zhu D, Kelly C, Terhakopian A, Novelli A et al (2001). NF- $\kappa \mathrm{B}$ is a critical determinant in NMDA receptormediated neuroprotection. J Neurochem 78: 254-264.

Lynch MA (2004). Long-term potentiation and memory. Physiol Rev 84: 87-136. 
MacQueen GM, Ramakrishnan K, Croll SD, Siuciak JA, Yu G, Young LT et al (2001). Performance of heterozygous brainderived neurotrophic factor knockout mice on behavioral analogues of anxiety, nociception, and depression. Behav Neurosci 115: 1145-1153.

Manji HK, Quiroz JA, Sporn J, Payne JL, Denicoff KA, Gray N et al (2003). Enhancing neuronal plasticity and cellular resilience to develop novel, improved therapeutics for difficult-to-treat depression. Biol Psychiatry 53: 707-742.

Marini AM, Jiang X, Wu X, Tain R, Zhu D, Okagaki P et al (2004). Brain-derived neurotrophic factor and NF- $\kappa$ B: from genes to phenotype. Restor Neurol Neurosci 22: 121-130.

Marini AM, Rabin SJ, Lipsky RH, Mocchetti I (1998). Activitydependent release of brain-derived neurotrophic factor underlies the neuroprotective effect of $\mathrm{N}$-methyl-D-aspartate. J Biol Chem 273: 29394-29399.

Mattson MP, Zhang Y, Bose S (1993). Growth factors prevent mitochondrial dysfunction, loss of calcium homeostasis, and cell injury, but not ATP depletion in hippocampal neurons deprived of glucose. Exp Neurol 121: 1-13.

Messaoudi E, Ying SW, Kanhema T, Croll SD, Bramham CR (2002). Brain-derived neurotrophic factor triggers transcription-dependent, late phase long-term potentiation in vivo. J Neurosci 22: 7453-7461.

Murphy DL, Lerner A, Rudnick G, Lesch KP (2004). Serotonin transporter: gene, genetic disorders, and pharmacogenetics. $\mathrm{Mol}$ Interv 4: 109-123.

Murray KD, Hayes VY, Gall CM, Isackson PJ (1998). Attenuation of the seizure-induced expression of BDNF mRNA in adult rat brain by an inhibitor of calcium/calmodulin-dependent protein kinases. Eur J Neurosci 10: 377-387.

Nakagawa S, Kim J-E, Lee R, Malberg JE, Chen J, Steffen C et al (2002). Regulation of neurogenesis in adult mouse hippocampus by cAMP and the cAMP response element-binding protein. J Neurosci 22: 3673-3682.

Nakata K, Ujike H, Sakai A, Uchida N, Nomura A, Imamura T et al (2003). Association study of the brain-derived neurotrophic factor (BDNF) gene with bipolar disorder. Neurosci Lett 337: $17-20$.

Neves-Pereira M, Mundo E, Muglia P, King N, Macciardi F, Kennedy JL (2002). The brain-derived neurotrophic factor gene confers susceptibility to bipolar disorder: evidence from a family-based association study. Am J Hum Genet 71: 651-655.

Prestridge DS (1991). SIGNAL SCAN: a computer program that scans DNA sequences for eukaryotic transcriptional elements. Comput Appl Biosci 7: 203-206.

Ribases M, Gratacos M, Armengol L, de Cid R, Badia A, Jimenez L et al (2003). Met66 in the brain-derived neurotrophic factor (BDNF) precursor is associated with anorexia nervosa restrictive type. Mol Psychiatry 8: 745-751.

Rudolph JG, White S, Sokolsky C, Bozak D, Mazzanti C, Lipsky RH et al (2002). Determination of melting temperature for variant detection using dHPLC: a comparison between an empirical approach and DNA melting prediction software. Genet Test 6: 169-176.
Rumajogee P, Madeira A, Vergé D, Hamon M, Miquel M-C (2002). Up-regulation of the neuronal serotoninergic phenotype in vitro: BDNF and cAMP share Trk B-dependent mechanisms. J Neurochem 83: 1525-1528.

Saarelainen T, Hendolin P, Lucas G, Koponen E, Sairanen M, MacDonald E et al (2003). Activation of the TrkB neurotrophin receptor is induced by antidepressant drugs and is required for antidepressant-induced behavioral effects. J Neurosci 23: 349-357.

Schulze TG, Hardy J, McMahon FJ (2003). Inconsistent designs of association studies: a missed opportunity. Mol Psychiatry 8: 770-772.

Sen S, Nesse RM, Stoltenberg SF, Li S, Gleiberman L, Chakravarti A et al (2003). A BDNF coding variant is associated with the NEO personality inventory domain neuroticism, a risk factor for depression. Neuropsychopharmacology 28: 397-401.

Sklar P, Gabriel SB, McInnis MG, Bennett P, Lim YM, Tsan G et al (2002). Family-based association study of 76 candidate genes in bipolar disorder: BDNF is a potential risk locus. Mol Psychiatry 7: 579-593.

Tabuchi A, Nakaoka R, Amano K, Yukimine M, Andoh T, Kuraishi $\mathrm{Y}$ et al (2000). Differential activation of brain-derived neurotrophic factor gene promoters I and III by $\mathrm{Ca}^{2+}$ signals evoked via $L$-type voltage-dependent and $N$-methyl-D-aspartate receptor $\mathrm{Ca}^{2+}$ channels. J Biol Chem 275: 17269-17275.

Tabuchi A, Sakaya H, Kisukeda T, Fushiki H, Tsuda M (2002). Involvement of an upstream stimulatory factor as well as cAMPresponsive element-binding protein in the activation of brainderived neurotrophic factor gene promoter I. J Biol Chem 277: 35920-35931.

Tao X, Finkbeiner S, Arnold DB, Shaywitz AJ, Greenberg ME (1998). $\mathrm{Ca}^{2+}$ influx regulates BDNF transcription by a CREB family transcription factor-dependent mechanism. Neuron 20: 709-726.

Tao X, West AE, Chen WG, Corfas G, Greenberg ME (2002). A calcium-responsive transcription factor, $\mathrm{CaRF}$, that regulates neuronal activity-dependent expression of BDNF. Neuron 33: 383-395.

Toda T, Momose Y, Murata M, Tamiya G, Yamamoto M, Hattori N et al (2003). Toward identification of susceptibility genes for sporatic Parkinson's disease. J Neurol Suppl 3: III40-III43.

Tsai SJ, Hong CJ, Yu YW, Chen TJ (2004). Association study of a brain-derived neurotrophic factor (BDNF) Val66Met polymorphism and personality trait and intelligence in healthy young females. Neuropsychobiology 49: 13-16.

Tsuang MT, Taylor L, Faraone SV (2004). An overview of the genetics of psychotic mood disorders. J Psychiatr Res 38: 3-15.

Xu B, Gottschalk W, Chow A, Wilson RI, Schnell E, Zang K et al (2000). The role of brain-derived neurotrophic factor receptors in the mature hippocampus: modulation of long-term potentiaton through a presynaptic mechanism involving TrkB. J Neurosci 20: 6888-6897.

Yan Q, Radeke MJ, Matheson CR, Talvenheimo J, Welcher AA, Feinstein SC (1997). Immunocytochemical localization of TrkB in the central nervous system of the adult rat. J Comp Neurol 378: 135-157. 